\title{
O Lúdico e a Cultura (Digital)
}

\author{
Thiago Falcão ${ }^{1}$ \\ Letícia Perani ${ }^{2}$
}

Não de hoje o jogo se enseja como uma temática crucial para compreender a sociedade. Se para fins de argumentação fugirmos das referências mais recorrentes, repetidas à exaustão nos trabalhos do campo dos game studies - Johan Huizinga e Roger Caillois - ainda seremos contemplados, em campos conexos, com nomes como Erving Goffman, Gregory Bateson, Jacques Derrida, Michel Maffesoli, para citar uns poucos. Cada um desses pensadores dedicou parte de sua obra para refletir acerca do lazer, do entretenimento, do jogo, enfim.

Legitimação, talvez, seja do que o jogo precise; não apenas como objeto acadêmico no campo da Comunicação, mas como fenômeno social responsável pela diversidade de articulações, aglomerações e comunidades experimentadas e observáveis na cultura contemporânea. Os nichos são os mais distintos o possível, e respondem, neste caso, pela pluralidade de temas tocados pela composição deste dossiê: o jogo é bem mais que o fenômeno dos video games, mais do que os puzzles em nossos smart phones: ele se encontra imbricado como espírito àquilo que chamamos de cultura contemporânea, ele é o macabro e o obscuro, o arcano, as nuances da representação teatral no nosso dia-a-dia um elemento de mediação definitiva em nossa relação com o mundo.

Não à toa, portanto, fazemos alusão a Huizinga nesta apresentação: nele o jogo - em sua multitude - se apresenta como elemento de geração, formador e

\footnotetext{
${ }^{1}$ Professor Adjunto do Curso de Jornalismo da Universidade Federal do Maranhão e Professor Visitante no Programa de Pós-Graduação em Comunicação da Universidade Anhembi Morumbi (UAM). Pós-doutorado em Comunicação e Audiovisual (UAM). E-mail: falc40@gmail.com

2 Professora do Instituto de Artes e Design da Universidade Federal de Juiz de Fora (IAD/UFJF), e coordenadora do projeto de extensão Design e Cultura dos Jogos Online. Doutora em Comunicação pelo PPGCom/Uerj.

E-mail: leticiaperani@yahoo.com.br
} 
definidor de fenômenos culturais. É nesse sentido que nos debruçamos, enfim, sobre os aspectos do entretenimento digital neste dossiê, certos de que em cada um deles jaz contemplada a discussão na qual o jogo - o momento de júbilo, sua voluntariedade e composição quase ritualística - é força agencial, se apresentando e apropriando das nuances do contexto digital contemporâneo.

A diversidade das formas e linguagens do entretenimento digital se reflete nos artigos desta edição. No artigo "A Virada Material dos Game Studies", os pesquisadores de jogos eletrônicos Thomas Apperley e Darshana Jayemane discutem os contextos materiais que envolvem os games, a partir da emergência de uma mudança nas abordagens acadêmicas sobre o assunto. Sua discussão é particularmente bem vinda porque traduz uma ânsia que se replica em vários trabalhos acerca do tema produzidos no Brasil. A partir de uma discussão sobre três vertentes que endereçam os jogos eletrônicos, Apperley e Jayemane sugerem caminhos para pesquisa e criticam metodologias - um exercício que possui certamente mérito - sobretudo no sentido em que clareia uma relação latente que os game studies possuem com aquilo que pode ser considerado uma ciência da comunicação.

Em "O Ciclo de Vida de um Meme: Delineamentos para o espalhamento a partir do ciberacontecimento em torno do caso da capivara-cachorro", Maria Clara Aquino Bittencourt e Christian Gonzatti discutem as etapas de elaboração, divulgação, viralização e decadência dos memes, conteúdos online tão presentes e populares entre os usuários da Internet no Brasil.

Já "Mais do que apenas dedos rápidos: narrativas e experiências de performances em League of Legends", de Tarcízio Macedo e Manuela do Corral Vieira, analisam o fenômeno League of Legends (ou LoL, como é mais conhecido), jogo online que atrai milhões de jogadores em todo o mundo, a partir de aspectos sociais, de performance e de interação. O humor dos vídeos online, e suas possibilidades de efetuar comentários sociais e políticos sobre acontecimentos da atualidade, é o destaque de Carla Montuori Fernandes e Patrícia Cristina de Lima em "O Humor Irônico dos Contratempos Políticos na websérie Porta dos Fundos". Com o artigo "O 'ao vivo' como promessa de 
participação e de autenticidade nos reality shows", Bruno Campanella e Melissa Ribeiro de Almeida demonstram como a modalidade de transmissão ao vivo evidenciam promessas de participação e de autenticidade, mesmo que não cumpridas, nos conteúdos televisivos.

As estranhas imagens e sons construídos com as distorções e (re)elaborações das linguagens digitais é o foco de Jamer Guterres de Mello e Mario Alberto Pires de Arruda em "Vaporwave: Deterioração e colagem de superfícies midiáticas", propondo que o movimento Vaporwave evidencia os próprios processos de composição destes conteúdos. Já Amanda Meschiatti Vasconcellos e Daniela Zanetti discutem as questões que envolvem a fama online em "(Web)celebridade: O sujeito ordinário e a narrativa cotidiana sob holofotes", afirmando que este fenômeno é parte do espírito do tempo da contemporaneidade. As questões políticas que envolvem as diferenças na representação de árabes e israelenses em jogos eletrônicos, a partir da teoria pós-colonial do Sul Global, é a perspectiva apresentada por Diego Granja do Amaral e José Messias Franco em "A imagem através do espelho: O sujeito Ocidente e a razão do poder em jogos documentais".

No artigo 'Videoclipe, interação e ludicidade”, Laan Mendes de Barros e Carlos Henrique Sabino Caldas discutem como a adoção de ferramentas interativas em sua exibição tornam os videoclipes mais participativos e, por consequência, mais lúdicos e complexos em seu consumo. Por fim, Wanderley Anchieta propõe, em “Mass Effect, No Man's Sky e os realismos nos games”, que a busca pelo realismo na representação gráfica nos jogos eletrônicos não implica, contudo, em algo necessário para a elaboração destes conteúdos digitais.

O intento deste dossiê, assim, oscila entre essas duas questões: de um lado acreditamos que ele oferece o índice de legitimação à qual o campo busca, sublinhando, ainda, o otimismo com o qual o compusemos. Por outro lado, a profusão de temáticas relacionadas ao lúdico sublinha que o esforço na busca por esta articulação (teórica, política) é absolutamente profícua e, em nossa 
esperança, possibilita diálogos para com a pesquisa no campo da Comunicação de forma mais ampla e sistemática.

\section{Referências}

HUIZINGA, J. Homo Ludens - O Jogo como em Elemento da Cultura. São Paulo: Perspectiva, [2001] 1938. 